\title{
Association of leisure-time physical activity with cognition by apolipoprotein-E genotype in persons aged 60 years and over: the National Health and Nutrition Examination Survey (NHANES-III)
}

This article was published in the following Dove Press journal:

Clinical Interventions in Aging

28 January 2012

Number of times this article has been viewed

\section{Thomas O Obisesan \\ Nisser Umar \\ Nivedh Paluvoi \\ Richard F Gillum}

Division of Geriatrics, Howard University Hospital, Washington, DC, USA
Correspondence: Thomas O Obisesan Division of Geriatrics, Department of Medicine, Howard University Hospital, 204I Georgia Ave, NW, Washington, DC, 20060, USA

$\mathrm{Tel}+\mathrm{I} 2028653397$

Fax +l 2028653777

Email tobisesan@howard.edu
Objective: To test the hypothesis that aerobic-related leisure-time physical activity (PA) is associated with better cognitive function and that the effect varies among apolipoprotein $\mathrm{E}$ (APOE) genotype groups.

Design: Cross-sectional study of persons examined in the Third National Health and Nutrition Examination Survey (NHANES-III; 1988-1994).

Setting: US noninstitutionalized population.

Participants and methods: From a sample of 7159 , aged $\geq 60$ years, we analyzed data for 1799 older American men and women who had information on PA, a short mental status examination (SMSE), and were genotyped at the apolipoprotein E gene locus.

Results: In the initial bivariate analysis, non- $\varepsilon 4$ carriers and $\varepsilon 4$-heterozygotes performed better than $\varepsilon 4$-homozygotes in the 60-69 age group. After controlling for multiple confounders including mobility limitation, PA correlated with a higher SMSE score in non- $\varepsilon 4$ carriers $(P=0.014)$, but not in $\varepsilon 4$ carriers $(P=0.887)$. At $\geq 70$ years, $P A$ also correlated with higher adjusted SMSE scores in non- $\varepsilon 4$ carriers $(P=0.02)$; but this association became nonsignificant after controlling for mobility limitation $(P=0.12)$.

Conclusion: In a nationally representative sample, PA was associated with enhanced cognition, an effect that was differentially influenced by apolipoprotein E genotype. Experimental studies are needed to determine whether or not PA can attenuate cognitive decline.

Keywords: cognition, physical activity, apolipoprotein E gene, aging

\section{Introduction}

Alzheimer's disease (AD) is the most common type of dementia, constituting two-thirds of all late-life dementias. ${ }^{1,2}$ Its prevalence increases about 15 -fold from 3\% among individuals aged $65-74$ years to $47 \%$ among persons aged $\geq 85$ years. ${ }^{3-6}$ In 2010 , the annual US health care cost for AD reached about US\$144 billion. ${ }^{7}$ Similarly, total 2010 health care, including long-term care payments for AD and other dementia care, was expected to reach US\$172 billion. $^{7}$ Given this cost and the projected increase in elderly population by the year 2050, identifying effective mechanisms to prevent AD is an important public health goal.

Until recently, the influence of lifestyle adaptation on AD risk had received very little attention in the scientific literature. Emerging evidence now indicates that PA can enhance cognitive processes ${ }^{8-18}$ Whereas many of such studies examined the type of physical activities performed, others focused on the relationship of the number, ${ }^{19}$ 
frequency, ${ }^{20}$ or intensity ${ }^{21}$ of such activities with cognitive processes. A summary of published literature by Colcombe and Kramer, using a meta-analysis of 18 studies, concluded that fitness training benefitted an array of neurocognitive process in nondemented older adults. ${ }^{22}$ Conclusions from these studies mostly suggest significant association of low and high levels of physical activity (PA) with reduced and enhanced cognitive processes, respectively; however, the sample sizes were often small, nonrepresentative, and lacked uniformity in their definition of PA and the characterization of the cognitive phenotype.

Despite the evidence showing that high levels of PA are mostly beneficial, significant interindividual variations of these benefits remain. This may suggest effect modification at the genetic level. Variation at the apolipoprotein E (APOE) gene locus is the most consistent nondeterministic genetic risk factor for late-onset Alzheimer's dementia. ${ }^{23-26}$ Its contribution to $\mathrm{AD}$ risk is graded across its three known common isoforms (E2, E3, and E4) in humans encoded by $\varepsilon 2, \varepsilon 3$, and $\varepsilon 4$ alleles. Whereas, $\varepsilon 2$ allele is associated with lower risk, $\varepsilon 4$ associates with increased AD risk, an effect that is differentially influenced by age. ${ }^{27-29}$ Interindividual variation in the $\varepsilon 4$ allele-associated risk may also indicate additional effect modification at the environment level such as imposed by lifestyle. A prior longitudinal study examined the potential benefits of interactions between APOE and PA, with varying results. ${ }^{19}$ Whether the APOE gene modifies the effects of PA on cognition in a nationally representative sample such as the Third National Health and Nutrition Examination Survey (NHANES-III) study is yet to be determined. We hypothesized that PA will associate with enhanced cognition and that this effect will differ with age and APOE genotype in a nationally representative sample of older Americans.

\section{Methods}

\section{Study subjects}

The NHANES-III was a cross-sectional, stratified, multistage probability sample of 33,994 civilian, noninstitutionalized Americans in the 50 states and the District of Columbia aged from 2 months to 99 years old, making it the first NHANES to include persons aged $\geq 75$ years. The study, conducted by the Center for Disease Control's National Center for Health Statistics between 1988 and 1994, oversampled Mexican Americans, African Americans, and those $>60$ years. ${ }^{30,31}$ Of persons aged $\geq 60$ years, 5724 (86\%) had an assessment of cognitive function. A subset of this sample (1799) included in this analysis were genotyped at the APOE locus.

\section{General assessments}

Overall, the questionnaires were designed for administration in a bilingual (English/Spanish) format so that respondents could be interviewed in their preferred language. During a home interview, an interviewer collected the demographic variables such as age, gender, and level of education to be used in this analysis.

\section{PA}

Participants were asked, "In the past month, did you engage in any leisure-time physical activity?" If their answer was "yes," they were asked, "In the past month, how often did you ...?" (specify number of times) for the following: jogging or running, riding a bicycle or exercise bicycle, swimming, aerobic dancing, other dancing, calisthenics or floor exercises, gardening or yard work, and weight lifting. ${ }^{32,33}$ Open-ended questions assessed up to four other activities. Participants were also asked about how often they walked $\geq 1$ mile. Persons responding "no times" to all of the activities above were classified "no PA." Mobility limitation was also categorized on the basis of participants' responses to two questions asking about difficulty experienced walking two or three blocks and walking up to ten steps without resting. Persons reporting no difficulty were considered to not have limited mobility. These two questions have been used by other investigators to assess mobility limitation. . $^{3435}$ Serious chronic illnesses included a self-reported history of chronic obstructive pulmonary disease, congestive heart failure, myocardial infarction, cancer, diabetes, and stroke.

\section{Assessment of cognitive function}

Questions assessing mental cognition were asked only of respondents aged $\geq 60$ years. The neuropsychological measures used in the NHANES-III study were selected to assess cognitive functions typically affected in dementia. ${ }^{36}$ The evaluations, including measures of learning and memory, were obtained during home interviews and at the mobile examination center. These questions, along with recall questions and "serial 3 subtraction" found on the adult questionnaire, constituted a short mental state examination (SMSE). ${ }^{36,37}$ Details of the content and administration of the SMSE used during the NHANES-III have been previously published. ${ }^{38}$ Overall scores on the SMSE calculated from the sum of orientation, recall, and attention ranged from 0 to 17 . The SMSE was carried out during a home examination in $8.6 \%$ of the sample for participants who were unable or unwilling to come to a mobile examination center for a complete examination. 


\section{Genetic data}

Blood lymphocytes were collected from participants aged $\geq 12$ years and stored in liquid nitrogen as cell cultures immortalized with Epstein-Barr virus. DNA in the form of crude cell lysates was made available for approved research projects for 7159 persons examined between 1991 and 1994. Genetic data generated from those projects from 1999 to 2006 were submitted to the National Center for Health Statistics and stored upon successful completion of a three-part quality-control analysis. We used data for participants genotyped at the APOE locus (dbSNP ID: rs7412 and rs429358). To maintain confidentiality of individual-level data, analysis occurred at the National Center for Health Statistics Research Data Center in Hyattsville, MD. Approval of the Howard University Institutional Review Board was obtained prior to the analysis.

\section{Statistical analysis}

Initial analyses using SAS 9.2 (SAS Institute, Cary, NC) included $t$-test and chi-square test and examined for group differences in age, gender, ethnicity, educational attainment, and body mass by level of self-reported history of PA, as well as the effects of PA on cognition within age strata. Using multiple regression analysis, we then examined the relationship of PA to cognition, while adjusting for a priori defined confounders. Given the declining levels of PA with age and lower levels of PA in Blacks than in Whites, model 1 included adjustment for age and ethnicity effects on cognition and physical function, whereas model 2 discounted the effects of chronic medical illnesses on cognitive processes and on PA levels. To discount the contribution of education on differences in performance on cognitive tasks ${ }^{39}$ and the association of body mass index (BMI) with cognition across populations, ${ }^{40,41}$ model 3 additionally adjusted for education and BMI. Given that persons with mobility limitation are less likely to exercise, this variable was included in model 4. Because of evidence indicating that the effect of APOE on cognition is probably influenced by age, ${ }^{27-29}$ and to further discern the effect of age from other predictors of cognitive outcome and important confounders, we constructed separate models for the age groups $60-69$ and $\geq 70$. Least square means adjusted for age, gender, ethnicity, and education were derived using analysis of variance (general linear model). Similar, but separate, models were constructed for APOE genotype groups. To mitigate sample-size limitation, we dichotomized the sample as non- $\varepsilon 4$ carriers ( $\varepsilon 4$ allele absent), and $\varepsilon 4$ carriers (at least one copy of $\varepsilon 4$ ).

To address the peculiarity of the multistage complex survey design of NHANES-III, final analyses were performed using SUDAAN (RTI International, Research Triangle Park, NC), software that accounts for the multistage sampling of NHANES-III in computing variance estimates. ${ }^{42}$ Appropriate sampling weights were used to account for oversampling and nonresponse. SUDAAN Proc Crosstab and Descript were used to estimate percentages and means, respectively, across groups. Proc Reg was used for linear regression.

\section{Results}

Overall, 56.9\% had any PA, while $43.1 \%$ did not. Those who engaged in any PA were relatively younger, more likely to be men, and had more formal education (Table 1). Compared with other ethnic groups, Whites in the sample were about twice as likely to engage in PA as Blacks and Mexican Americans $(61.6 \%, 32.8 \%$, and $38.9 \%$, respectively). However, both groups had comparable BMI. APOE genotype was in Hardy-Weinberg equilibrium $(P<0.05)$. The respective frequencies of allele combinations paralleled those reported in the literature. In the entire sample, Blacks were more likely to be carriers and homozygotes for the risk allele (ع4) (39.19 and 4.89, respectively), compared with Whites (28.02 and 2.19, respectively), and Mexican Americans (19.34 and 1.61), respectively.

Between the ages of 60 and 69 years (Figures 1 and 2), persons who performed PA tended to score higher on the SMSE among heterozygotes and noncarriers but not among

Table I Characteristics of the sample (percent by leisure-time physical activity)

\begin{tabular}{|c|c|c|c|}
\hline $\begin{array}{l}\text { Leisure-time } \\
\text { physical activity }\end{array}$ & Yes & No & $P$ value \\
\hline \multicolumn{4}{|l|}{ Age (years) } \\
\hline $60-69$ & 60.22 & 39.78 & 0.0134 \\
\hline$\geq 70$ & 53.66 & 46.34 & \\
\hline \multicolumn{4}{|l|}{ Gender } \\
\hline Men & 56.89 & 43.11 & $<0.0001$ \\
\hline Women & 49.67 & 50.33 & \\
\hline \multicolumn{4}{|l|}{ Ethnicity } \\
\hline White & 61.55 & 38.35 & $<0.0001$ \\
\hline Black & 32.81 & 67.19 & \\
\hline Mexican & 38.94 & 61.06 & \\
\hline Other & 32.22 & 67.78 & \\
\hline \multicolumn{4}{|l|}{ Education (years) } \\
\hline$<12$ & 47.00 & 53.00 & 0.0002 \\
\hline 12 & 59.05 & 40.95 & \\
\hline$>12$ & 66.67 & 33.33 & \\
\hline \multicolumn{4}{|l|}{ Body mass index } \\
\hline$<25$ & 56.87 & 43.13 & $0.965 I$ \\
\hline $25-29$ & 57.40 & 42.60 & \\
\hline$\geq 30$ & 56.13 & 43.87 & \\
\hline
\end{tabular}




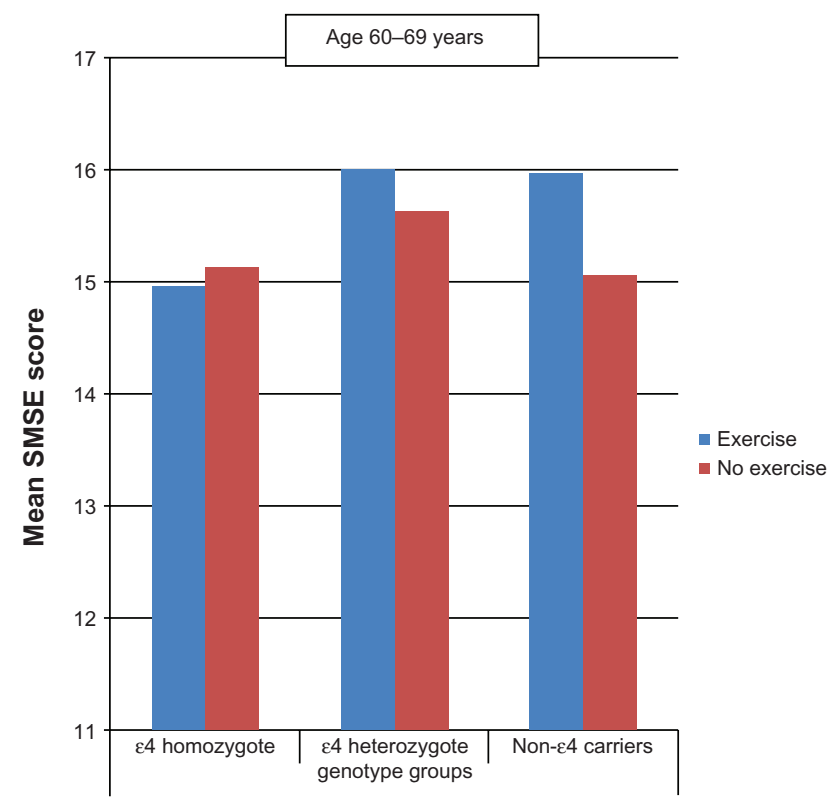

Figure I Mean short mental state examination (SMSE) score by physical activity and apolipoprotein E genotype (age 60 to 69 years).

homozygotes. At age $\geq 70$ years, similar associations were observed not only in heterozygotes and noncarriers but also in homozygotes.

\section{Multiple regression analysis}

In the initial analysis restricted to the non- $\varepsilon 4$ carrier genotype group aged 60-69 years and adjusted for age and ethnicity (model 1), PA was significantly associated with cognitive performance $(\beta=0.68 \pm 0.2 ; P=0.006)$ (Table 2$)$. This model accounted for $9.8 \%$ of the observed variance. With additional

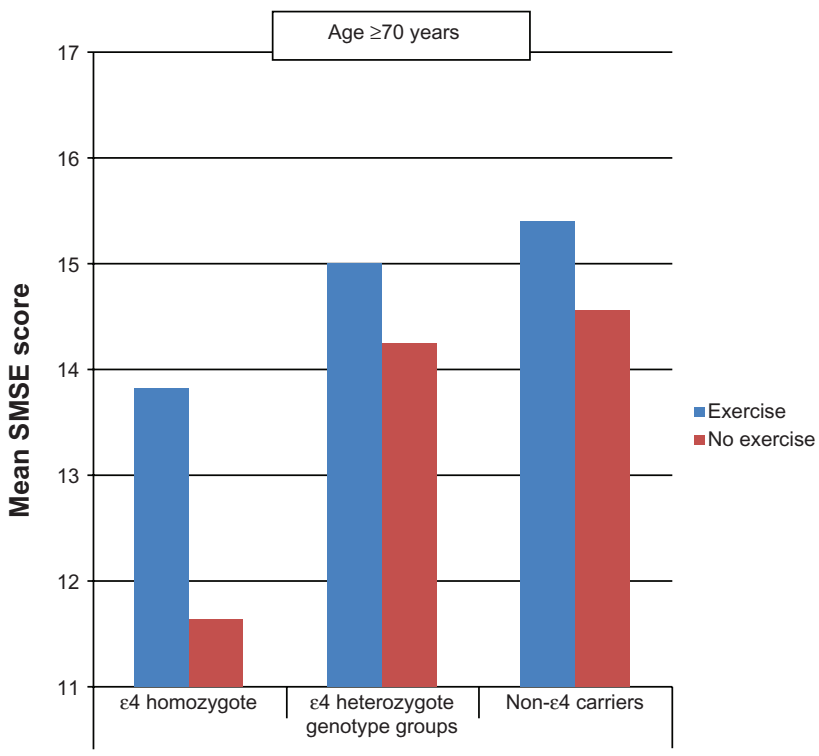

Figure 2 Mean short mental state examination (SMSE) score by leisure-time physical activity and apolipoprotein E genotype (age $\geq 70$ years). adjustment for serious chronic medical illnesses (congestive heart failure, chronic obstructive pulmonary disease, cancer, diabetes, myocardial infarction, and stroke) (model 2), this statistically significant association remained unchanged ( $\beta=0.68 \pm 0.2 ; P=0.007)$. However, after accounting for differences in BMI and education (model 3), PA maintained a statistically significant but reduced association with cognitive function $(\beta=0.52 \pm 0.2 ; P=0.007)$. In the last model, controlled for mobility limitation in non- $\varepsilon 4$ carriers (model 4 ), the significant association of PA ( $\beta$ coefficient $0.43 \pm 0.2, P=0.014)$ with SMSE score persisted though slightly attenuated. However, among the $\varepsilon 4$ carriers of this age group, PA did not significantly associate with cognitive performance.

We also examined the relationship of PA to SMSE in the $>70$ year old age group (Table 3 ). In noncarriers, PA associated with performance on the cognitive test in models 1,2 , and 3 . With the introduction of mobility limitation $(\beta=-0.78 \pm 0.2, P<0.001)$ in model 4 , the association of PA to cognitive performance became attenuated and nonsignificant $(\beta=0.37 \pm 0.2, P=0.117)$. Among $\varepsilon 4$ carriers, similar associations with cognitive performance were observed in models $1-4$, but did not attain statistical significance. This could be due to the smaller sample size.

\section{Discussion}

PA was associated with better performance on cognitive tasks in a sample of age $\geq 60$ non- $\varepsilon 4$ carriers but not in carriers. These findings were independent of linear age, gender, ethnicity, education, income, and history of serious chronic illness. This adds to growing evidence that increased levels of PA may offer an important primary intervention strategy to attenuate neurocognitive loss, especially in non- $\varepsilon 4$ carriers. Delay in significant cognitive loss and considerable public heath impact are likely to be realized if these findings are confirmed in experimental studies.

Evidence showing that PA can enhance cognition includes cross-sectional, prospective studies and a limited number of controlled trials. ${ }^{8-11,17-20,22}$ Many studies examined the effects of aerobic fitness on cognition in nondemented older adults, while others determined whether or not lifestyle factors can reduce or delay late-onset Alzheimer's dementia. In concordance with our observations from this study, a beneficial effect of PA was often reported. ${ }^{19-21,43}$ Whereas Albert and colleagues reported that strenuous but not moderate intensity daily PA enhanced cognition, ${ }^{44}$ Yaffe et al showed that moderate daily PA can also improve cognitive processes. ${ }^{45}$ Together, these reports are consistent with our hypothesis and results from this study that PA is beneficial to cognitive health. 


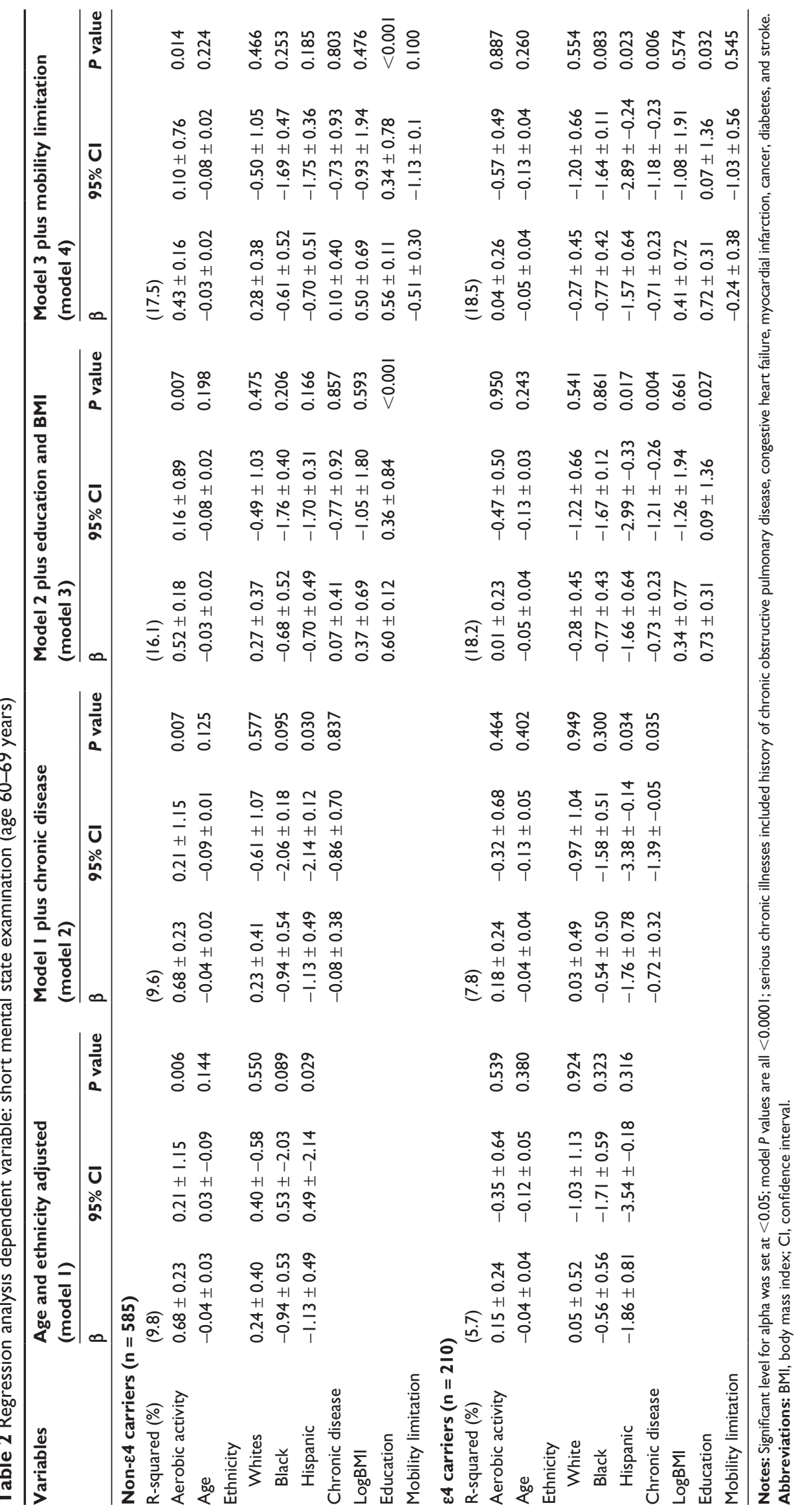




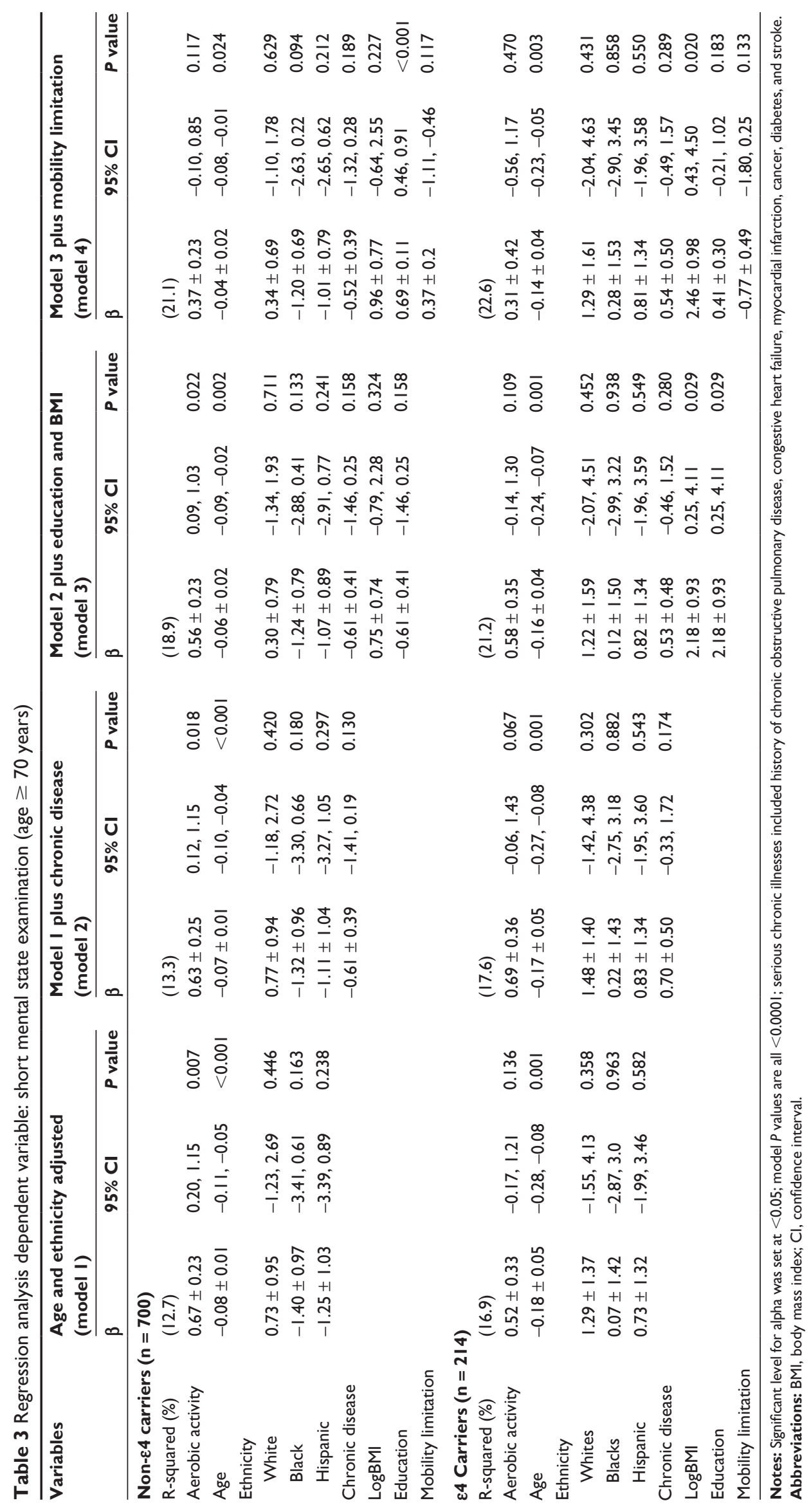


However, unlike previous cross-sectional studies, the use of a representative sample of US noninstitutionalized population enhanced the generalizability of our findings beyond that previously reported in cross-sectional studies.

Consistent with our second hypothesis, the relationship of PA to performance on the SMSE test varied with APOE genotype and age group. In the adjusted model, the apparent relationship between APOE and PA observed in the unadjusted model became attenuated in those aged $>70$ years. This may suggest that the APOE effect becomes attenuated with age, allowing other determinants of cognitive function such as PA to become more apparent. Similar to the cognitively beneficial effects of PA observed in non- $\varepsilon 4$ carriers in our study, Podewils et al demonstrated that performance of $\geq 4$ types of activity lowered dementia risk at age $\geq 65$ years in the Cardiovascular Health Cognition Study, an effect that was marked in non- $\varepsilon 4$ carriers but absent in $\varepsilon 4$ carriers. ${ }^{19}$ Conversely, we confirmed a lack of association of PA with cognitive performance in $\varepsilon 4$ carriers in the 60-69 age group. Persons suffering from serious medical illnesses may perform at lower levels of PA and have lower cognition. However, the statistically significant association of PA with enhanced cognition at age 60-69 years in our final model suggests that the association of PA with enhanced cognition in the younger non- $\varepsilon 4$ carriers is likely independent of mobility limitation and chronic medical illnesses.

An additional important finding from this study is the improved performance in the $>70$ age group exercisers compared with nonexercisers in all genotype groups, suggesting that the favorable effects of PA in this group may not be significantly influenced by the $\varepsilon 4$ allele of the APOE gene (Figure 2). The favorable effects of PA on memory in non- $\varepsilon 4$ carriers remained unaltered, notwithstanding adjustment for serious chronic medical illness, but not after accounting for the effect of mobility limitation. However, a three-group ( $\varepsilon 4$-homozygote, $\varepsilon 4$-heterozygote, and noncarriers) analysis to confirm that PA can enhance cognition at age $\geq 70$ years regardless of genotype group was constrained by sample size.

Because mobility limitation is a surrogate marker for PA, its significant association with poorer performance on cognitive tests after discounting the effects of serious chronic medical illness supports its role as an indicator of sedentary lifestyle. Previously, it was suggested that pathologies underlining frailty may partially explain the association of low levels of PA with poor cognitive performance. ${ }^{46}$ The coexistence of frailty with serious chronic medical condition and low BMI prompted us to examine their contributions to cognitive outcome in our sample. However, the significant effect of PA after adjustments for serious chronic medical conditions and BMI, makes frailty a less tenable explanation for our findings in older adults but supports mobility limitation as a surrogate marker for low levels of PA. Given the nonspecific pattern of association of APOE genotype groups with limitation in physical function, this relationship probably does not explain our findings either.

Contrary to studies reporting a beneficial effect of PA and/or aerobic fitness on neurocognitive processes, few have reported negative results. ${ }^{47,48}$ Verghese et al reported that a one-point increment in the PA score did not significantly improve performance on cognitive tasks, ${ }^{47}$ and that levels of PA did not associate with incident amnestic mild cognitive impairment. ${ }^{48}$ However, the authors failed to account for a few important components of PA such as walking, gardening/yard work, and house chores. Interestingly, our observation of no association in the 60-69 age group $\varepsilon 4$-carriers is also analogous to the overall conclusions of Verghese et al, except that such subgroup analyses were not considered by the authors. Such methodological differences in the assessments of cognition and PA may contribute to inconsistencies in the literature. In comparison with previous cross-sectional studies, this study has the advantage of adjustment for serious chronic illnesses and mobility limitation, is age-specific, and involves APOE genotype-stratified analysis in addition to a representative sample. Though the mechanisms by which APOE comediates differential PA-induced changes in cognition may involve its role in lipid metabolism, further clarification of this process is needed.

\section{Advantages and limitations}

NHANES-III is the largest study to provide populationbased data on the association of cognitive function and PA in a nationwide representative sample of older Americans. Because age is one of the most important risk factors for dementia, the relatively large sample size of the NHANES-III permits age-stratified analysis, adjustment for multiple confounders, and, therefore, more detailed assessment of the relationship of PA with cognitive outcome. Limitations of this study include possible bias from survey nonresponse and from missing values for some variables and the large number without APOE data.

Due to its cross-sectional nature, the study does not provide information on the temporal sequence of PA with SMSE score. For questionnaires administered in the Hispanic language, translational bias cannot be excluded in spite of rigorous staff training and standardizations. Randomized controlled trials 
using a more rigorous standardized aerobic exercise-training protocol together with detailed neuropsychological measures are needed to determine the duration, intensity, frequency, and ultimately the volume of exercise that are beneficial.

\section{Conclusion}

In a large national sample of noninstitutionalized Americans aged $\geq 60$ years, PA associated with better cognitive outcomes. Between the ages of 60 and 69 years, this effect varied by APOE gene group, the effects being observed only in non- $\varepsilon 4$ carriers. Randomized controlled trials are needed to establish causality. Also, the APOE genotype or its genotype must be taken into account while designing such studies. These may lay the groundwork for the prescription of aerobic training as an intervention to attenuate AD risk in those at risk.

\section{Acknowledgments}

Thomas Obisesan and Richard Gillum participated in the conceptualization, data analysis, interpretation, and manuscript preparation. Nisser Umar and Nivedh Paluvoi participated in the interpretation and manuscript preparation. Biostatistician support was provided by Dr John Kwagyan of Howard University General Clinical Research Center.

\section{Disclosure}

This work is supported by K23 AG00980 (TOO), RO1 AG031517-01A2, RR10284 (HU), and AG02213 (RCG). The content is solely the responsibility of the authors and does not necessarily represent the official views of the National Institute on Aging of the National Institutes of Health or the National Center for Health Statistics.

\section{References}

1. Ritchie K. Dementia in the elderly. Neurology. 1995;45(11): 2112-2113.

2. de Jesús Llibre J, Fernandez Y, Marcheco B, et al. Prevalence of dementia and Alzheimer's Disease in a Havana Municipality: a community-based study among elderly residents. MEDICC Rev. 2009;11(2):29-35.

3. Evans DA, Funkenstein HH, Albert MS, et al. Prevalence of Alzheimer's disease in a community population of older persons. Higher than previously reported. JAMA. 1989;262(18):2551-2556.

4. Brookmeyer R, Evans DA, Hebert L, et al. National estimates of the prevalence of Alzheimer's disease in the United States. Alzheimers Dement. 2011;7(1):61-73.

5. Cornutiu G. The incidence and prevalence of Alzheimer's disease. Neurodegener Dis. 2011;8(1-2):9-14.

6. Gutterman EM, Markowitz JS, Lewis B, Fillit H. Cost of Alzheimer's disease and related dementia in managed-medicare. J Am Geriatr Soc. 1999;47(9):1065-1071.

7. Alzheimer's Association. 2010 Alzheimer's disease facts and figures. Alzheimer's and Dementia. 2010;(6):158-194

8. Burns A, Iliffe S. Alzheimer's disease. BMJ. 2009;338:b158.
9. Steinberg M, Leoutsakos JM, Podewils LJ, Lyketsos CG. Evaluation of a home-based exercise program in the treatment of Alzheimer's disease: the Maximizing Independence in Dementia (MIND) study. Int J Geriatr Psychiatry. 2009;24(7):680-685.

10. Weih M, Abu-Omar K, Esselmann H, et al. Physical activity and prevention of Alzheimer's dementia: current evidence and feasibility of an interventional trial. Fortschr Neurol Psychiatr. 2009;77(3):146-151. German.

11. Wu S, Liang J, Miao D. Physical activity and cognitive function in Alzheimer disease. JAMA. 2009;301(3):273; author reply 273-274.

12. Angevaren M, Vanhees L, Nooyens AC, Wendel-Vos CG, Verschuren WM. Physical activity and 5-year cognitive decline in the Doetinchem cohort study. Ann Epidemiol. 2010;20(6):473-479.

13. Middleton LE, Yaffe K. Targets for the prevention of dementia. J Alzheimers Dis. 2010;20(3):915-924.

14. Middleton LE, Yaffe K. Promising strategies for the prevention of dementia. Arch Neurol. 2009;66(10):1210-1215.

15. Barnes DE, Whitmer RA, Yaffe K. Physical activity and dementia: The need for prevention trials. Exerc Sport Sci Rev. 2007;35(1):24-29.

16. Lucia A, Ruiz JR. Exercise is beneficial for patients with Alzheimer's disease: a call for action. Br J Sports Med. 2011;45(6):468-469.

17. Yu F, Nelson NW, Savik K, Wyman JF, Dysken M, Bronas UG. Affecting Cognition and Quality of Life via Aerobic Exercise in Alzheimer's Disease. West J Nurs Res. 2011. Epub Sep 12.

18. Vreugdenhil A, Cannell J, Davies A, Razay G. A community-based exercise programme to improve functional ability in people with Alzheimer's disease: a randomized controlled trial. Scand J Caring Sci. 2011. Epub May 12.

19. Podewils LJ, Guallar E, Kuller LH, et al. Physical activity, APOE genotype, and dementia risk: findings from the Cardiovascular Health Cognition Study. Am J Epidemiol. 2005;161(7):639-651.

20. Larson EB, Wang L, Bowen JD, et al. Exercise is associated with reduced risk for incident dementia among persons 65 years of age and older. Ann Intern Med. 2006;144(2):73-81.

21. Rovio S, Kareholt I, Helkala EL, et al. Leisure-time physical activity at midlife and the risk of dementia and Alzheimer's disease. Lancet Neurol. 2005;4(11):705-711.

22. Colcombe $\mathrm{S}$, Kramer AF. Fitness effects on the cognitive function of older adults: a meta-analytic study. Psychol Sci. 2003;14(2):125-130.

23. Saunders AM, Schmader K, Breitner JC, et al. Apolipoprotein E epsilon 4 allele distributions in late-onset Alzheimer's disease and in other amyloid-forming diseases. Lancet. 1993;342(8873):710-711.

24. Saunders AM, Strittmatter WJ, Schmechel D, et al. Association of apolipoprotein E allele epsilon 4 with late-onset familial and sporadic Alzheimer's disease. Neurology. 1993;43(8):1467-1472.

25. Wolk DA, Dickerson BC; for the Alzheimer's Disease Neuroimaging Initiative. Apolipoprotein E (APOE) genotype has dissociable effects on memory and attentional-executive network function in Alzheimer's disease. Proc Natl Acad Sci U S A. 2010;107(22):10256-10261.

26. Basak JM, Kim J. Differential effects of ApoE isoforms on dendritic spines in vivo: linking an Alzheimer's disease risk factor with synaptic alterations. J Neurosci. 2011;30(13):4526-4527.

27. Christensen H, Batterham PJ, Mackinnon AJ, et al. The association of APOE genotype and cognitive decline in interaction with risk factors in a 65-69 year old community sample. BMC Geriatr. 2008;8:14.

28. Crivello F, Lemaitre H, Dufouil C, et al. Effects of ApoE-epsilon4 allele load and age on the rates of grey matter and hippocampal volumes loss in a longitudinal cohort of 1186 healthy elderly persons. Neuroimage. 2010;53(3):1064-1069.

29. Greenwood PM, Lambert C, Sunderland T, Parasuraman R. Effects of apolipoprotein E genotype on spatial attention, working memory, and their interaction in healthy, middle-aged adults: results From the National Institute of Mental Health's BIOCARD study. Neuropsychology. 2005;19(2):199-211.

30. Plan and operation of the Third National Health and Nutrition Examination Survey, 1988-1994. Series 1: programs and collection procedures. Vital Health Stat 1. 1994;(32):1-407. 
31. Seidel GK, Millis SR, Lichtenberg PA, Dijkers M. Predicting bowel and bladder continence from cognitive status in geriatric rehabilitation patients. Arch Phys Med Rehabil. 1994;75(5):590-593.

32. Crespo CJ, Keteyian SJ, Heath GW, Sempos CT. Leisure-time physical activity among US adults. Results from the Third National Health and Nutrition Examination Survey. Arch Intern Med. 1996;156(1):93-98.

33. White L, Petrovitch H, Hardman J, et al. Cerebrovascular pathology and dementia in autopsied Honolulu-Asia Aging Study participants. Ann NY Acad Sci. 2002;977:9-23.

34. Kelley-Moore JA, Ferraro KF. Functional limitations and religious service attendance in later life: barrier and/or benefit mechanism? J Gerontol B Psychol Sci Soc Sci. 2001;56(6):S365-S373.

35. Gillum RF. Frequency of attendance at religious services and leisure-time physical activity in American women and men: the Third National Health and Nutrition Examination Survey. Ann Behav Med. 2006;31(1):30-35.

36. Albert M, Smith LA, Scherr PA, Taylor JO, Evans DA, Funkenstein HH. Use of brief cognitive tests to identify individuals in the community with clinically diagnosed Alzheimer's disease. Int J Neurosci. 1991;57(3-4):167-178.

37. Lichtenberg PA, Christensen B. Extended normative data for the Logical Memory subtests of the Wechsler Memory Scale-Revised: responses from a sample of cognitively intact elderly medical patients. Psychol Rep. 1992;71(3 Pt 1):745-746.

38. Obisesan TO, Obisesan OA, Martins S, et al. High blood pressure, hypertension, and high pulse pressure are associated with poorer cognitive function in persons aged 60 and older: the Third National Health and Nutrition Examination Survey. J Am Geriatr Soc. 2008;56(3): 501-509.
39. Dilworth-Anderson P, Hendrie HC, Manly JJ, Khachaturian AS, Fazio S. Diagnosis and assessment of Alzheimer's disease in diverse populations. Alzheimers Dement. 2008;4(4):305-309.

40. Luchsinger JA, Gustafson DR. Adiposity and Alzheimer's disease. Curr Opin Clin Nutr Metab Care. 2009;12(1):15-21.

41. Profenno LA, Porsteinsson AP, Faraone SV. Meta-Analysis of Alzheimer's Disease Risk with Obesity, Diabetes, and Related Disorders. Biol Psychiatry. 2010;67(6):505-512.

42. Kleinbaum D. Logistic Regression: A Self Learning text. Statistics in the Health Sciences. New York: Springer; 1992.

43. Kramer AF, Erickson KI, Colcombe SJ. Exercise, cognition, and the aging brain. J Appl Physiol. 2006;101(4):1237-1242.

44. Albert MS, Jones K, Savage CR, et al. Predictors of cognitive change in older persons: MacArthur studies of successful aging. Psychol Aging. 1995;10(4):578-589.

45. Yaffe K, Barnes D, Nevitt M, Lui LY, Covinsky K. A prospective study of physical activity and cognitive decline in elderly women: women who walk. Arch Intern Med. 2001;161(14):1703-1708.

46. Samper-Ternent R, Al Snih S, Raji MA, Markides KS, Ottenbacher KJ. Relationship between frailty and cognitive decline in older Mexican Americans. J Am Geriatr Soc. 2008;56(10):1845-1852.

47. Verghese J, Lipton RB, Katz MJ, et al. Leisure activities and the risk of dementia in the elderly. $N$ Engl J Med. 2003;348(25):2508-2516.

48. Verghese J, LeValley A, Derby C, et al. Leisure activities and the risk of amnestic mild cognitive impairment in the elderly. Neurology. 2006;66(6):821-827.
Clinical Interventions in Aging

\section{Publish your work in this journal}

Clinical Interventions in Aging is an international, peer-reviewed journal focusing on evidence-based reports on the value or lack thereof of treatments intended to prevent or delay the onset of maladaptive correlates of aging in human beings. This journal is indexed on PubMed Central, MedLine, the American Chemical Society's 'Chemical Abstracts Ser-

\section{Dovepress}

vice' (CAS), Scopus and the Elsevier Bibliographic databases. The manuscript management system is completely online and includes a very quick and fair peer-review system, which is all easy to use. Visit http://www.dovepress.com/testimonials.php to read real quotes from published authors. 